
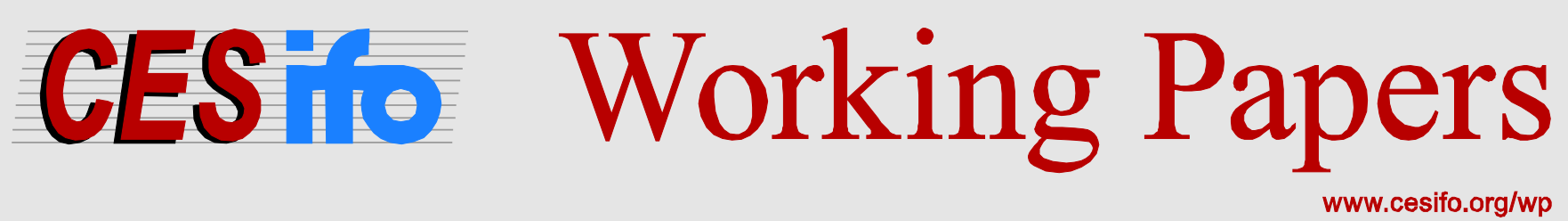

\title{
Climate Change and Migration: A Dynamic Model
}

\author{
Charles F. Mason
}

\author{
CESIFO WORKING PAPER NO. 6148 \\ CATEGORY 10: ENERGY AND CLIMATE ECONOMICS \\ OCTOBER 2016
}

An electronic version of the paper may be downloaded

- from the SSRN website:

- from the RePEc website:

- from the CESifo website:

www.SSRN.com

www.RePEc.org

www.CESifo-group.org/wp 


\title{
Climate Change and Migration: A Dynamic Model
}

\begin{abstract}
In this paper I explore a model where citizens of a country vulnerable to damages from climate change may migrate to a second country, from which a steady stream of greenhouse gases occur. If this migration imposes costs on the emitting country, then migration induces a sort of pseudo carbon tax.via political economic forces. This pseudo tax creates an incentive for the country receiving the flow of immigrants to lower its emissions, offering an offset to the costs incurred as a result of climate change. I show that the long run carbon stock, and the entire time path of production (and hence emissions), is smaller in the presence of migration. I discuss various comparative dynamics, for both the path of production and the long run atmospheric carbon stock.
\end{abstract}

JEL-Codes: Q540.

Keywords: transboundary pollution, migration, optimal control.

\author{
Charles F. Mason \\ Department of Economics \& Finance \\ University of Wyoming \\ USA - Laramie, WY 82071 \\ bambuzlr@uwyo.edu
}

This version: October 9, 2016

I thank, without implicating, participants in the CESifo workshop on migration and climate change for lively discussion. I am particularly grateful to Matthias Kalkuhl and Jesús Fernández-Huertas Moraga. The usual disclaimer applies. 


\section{Introduction}

With the recent ratification of the Paris Agreement, the glimmer of a global solution to climate change has appeared. Even so, many millions or people are likely to be displaced as a result of the climate change we are almost certain to experience in the coming years. Impacts such as sea level rise and increase exposure to extreme weather events have been associated with climate change (IPCC, 2014, p. 16); such events are "projected to increase displacement of people" (IPCC, 2014, p. 73). Indeed, a recent World Bank report argues that migration is likely to become an increasingly important adaptation method for responding to climate change Hallegatte et al. (2016, p. 161).

Individuals who originally reside in at-risk areas, such as low-lying areas, are particularly likely to migrate (McLeman and Smit, 2006). For example, a 2008 study finds that over one-fifth of households affected by tidal-surge floods, and roughly one-sixth of households affected by riverbank erosion, migrated to safer areas (Black et al., 2011, p. 448) . A recent World Bank report says "a significant deterioration of climatic conditions would lead to an increase of about one-tenth to one-fifth of current migration levels" and "in the future, as the effects of climate change intensify, environmentally induced migration is ex-

pected to increase" Hallegatte et al. (2016, p. 161). ${ }^{1}$ Bangladesh is particularly vulnerable (Hallegatte et al. 2016, p. 8, Figure O.6b). There, moving to cities has become a common coping strategy in the face of flooding (Black et al., 2011, p. 448). Throughout the world, pressures to migrate seem likely to persist (Black et al., 2011).

Such migration has important consequences. For example, the Fifth Assessment Report 
of the United Nations Intergovernmental Panel on Climate Change argues that migration out of low-lying areas will likely cause "loss of sense of place and cultural identity" (IPCC, 2014, p. 98). Such psychological costs are in addition to the financial burdens migrants must bear in order to relocate. But the fact that people would incur such costs underscores the substantial loss in utility associated with increased exposure to climate-related damages.

A substantial literature has recently developed that analyzes the potential for climate change to induce migration (Millock, 2015). My approach in this paper is to turn the approach typically taken in extant literature on its head, by asking if in-migration might induce polluting countries to lower their emissions. In particular, if such countries incur costs associated with the in-migration, as recent events in Europe have so painfully demonstrated, might the desire to reduce in-migration costs create a sort of pseudo carbon tax? I find that this channel can indeed create an incentive for polluting countries to reduce their emissions so as to reduce migratory incentives. One might think of the mechanisms leading to such an outcome as the result of lobbying by anti-immigration forces, where these groups influence the government of the polluting country to reduce its emissions so as to reduce climate change and, thereby, immigration tendencies. With such an interpretation, the channel I explore is a variant of political economy. This approach is, I believe, largely unexplored in the extant literature. ${ }^{2}$

I study the implications for in-migration to encourage reductions in greenhouse-gas emissions. I develop a dynamic model involving the interaction between two countries, an upstream country (whom I refer to as "country 1") that generates a flow of emissions and a 
downstream country (whom I refer to as "country 2") that is the source of migration. The emissions are associated with a good produced only in country 1 that is consumed in both countries. ${ }^{3}$ People living in country 2 are assumed to bear larger damages than people living in country 1 , which creates a motivation for some citizens in country 2 to migrate to country 1. I consider four dynamic optimization problems. In the first two problems migration is not possible, while in the second two it is feasible. Within each of these two classes, I analyze two problems: the private optimization problem for a decision-maker in country 1 who only cares about the present discounted flow of net benefits (utility less climate-related damages) to its citizens, and the social optimization problem for a mythical social planner who cares about the present discounted value of net benefits for all citizens (i.e., combined utility less all climate-related damages). I show that the potential for migration lowers the long run carbon stock, as well as production rates. The degree to which output levels, and hence emission flows, are reduced depends on key parameters: differences in the initial distribution of population between the two countries, the slopes of demand and marginal production cost, the rate of decay in the carbon stock, and the marginal cost to country 1 of in-migration. $^{4}$

Two examples illustrate the general idea. The first example involves India, currently the third-largest $\mathrm{CO}_{2}$ emitter in the world, and neighboring countries such as Bangladesh, Indonesia and Pakistan. In the recent Paris negotiations, India expressed concerns about curtailing its emissions, citing a desire to encourage economic growth. This inchoate growth is likely to be tied to increased use of coal, and hence is tied to substantial carbon emissions. 
Accordingly, any phenomenon that encourages India to lower its greenhouse gas emissions may generate important reductions in climate-related damages. Increased climate-related effects in nearby countries, such as Bangladesh, Indonesia and Pakistan, seem likely to trigger migration at some point, perhaps into India. ${ }^{5}$ This combination of events suggests a potential offsetting incentive upon Indian decision-makers.

A second example involves the United States (US), currently the second-largest $\mathrm{CO}_{2}$ emitter in the world, and Mexico, a major source of migration into the US. Similar to the first example, the country from which migration occurs is likely to experience important climate-related damages, particularly to agriculture. Indeed, there is some evidence that such influences have a historical antecedent: both Munshi (2003) and Barrios Puente et al. (2015) find that decreases in precipitation in Mexico, a likely outcome of climate change, increase migration from Mexico to the US. As in the first example, to the extent that US decision-makers perceive Mexican immigrants impose costs upon their constituents they have an incentive to undertake actions that would reduce migratory tendencies. One particular action is to reduce $\mathrm{CO}_{2}$ emissions, for example by reducing outputs that are linked to emissions. $^{6}$

The rest of the paper is organized as follows. Section 2 develops the dynamic model. In section 3, I describe the general solutions in the absence of migration for both the private optimization problem facing the upstream country and the social optimization problem. In section 4 , I work through the private and social optimization problems when migration is feasible. In section 5, I analyze a specific form of the problems when migration is feasible, 
where demand, marginal cost and climate-related damages are linear functions; using this "linear-quadratic" framework facilitates the development of closed form solutions. I then compare the optimal paths of production and carbon stocks with and without migration. Concluding remarks are offered in section 6 .

\section{Modeling preliminaries}

There are two countries, 1 and 2. I will often refer to country 1 as the "upstream" country and country 2 as the "downstream" country. A single consumption good is produced only in 1 with a given fixed endowment of factors of production and a given technology. The associated aggregate cost is described by the increasing and convex function $c(Q)$, where $Q$ is the total amount produced in country 1 . From this total amount, a quantity $Q_{1}$ is consumed in country 1; the remaining amount $Q_{2}=Q-Q_{1}$ is exported to country 2 . There is a fixed total population, which I normalize to one; I denote the population residing in country 1 as $\alpha$, which initially equals $\alpha_{0}$. Consumers are homogeneous within each country, but are heterogeneous across countries; I denote per-capita utility in country $i=1,2$ as $u_{i}\left(Q_{i}\right)$. In the absence of any frictions to trade, the volume of the product that is consumed in country 1 adjusts so as to equate marginal utility across the two countries:

$$
u_{1}^{\prime}\left(Q_{1}\right)=u_{2}^{\prime}\left(Q-Q_{1}\right) ;
$$

the common value of marginal utility is also equal to $p(Q)$, the price of the commodity at the total level of production. I note that this arbitrage condition implies 


$$
\partial Q_{1} / \partial Q=u_{2}^{\prime \prime} /\left[u_{1}^{\prime \prime}+u_{2}^{\prime \prime}\right]
$$

Production of the consumption good results in a flow of carbon emissions; for simplicity I assume a fixed proportions relation, where each unit of output generates one unit of carbon emissions. These emissions contribute to the atmospheric stock of carbon, $Z$. The stock is also subject to a constant rate of decay, $k$, so that $Z$ evolves according to the following equation of motion: ${ }^{7}$

$$
\dot{Z}=Q-k Z \text {. }
$$

I assume that citizens in country 2 suffer larger per-capita damages from the stock of pollution than do citizens in country 1 . I denote the per-capita damages in country 1 as $d(Z)$ and the per-capita damages in country 2 as $\beta d(Z)$, where $\beta>1$. I also assume that there are no damages from the flow of emissions. The damage function $d(Z)$ is an increasing and weakly convex function of the carbon stock (Schlenker and Roberts, 2009).

Citizens of country 2 are tempted to relocate to country 1 , so as to reduce their exposure to damages arising from the carbon stock. I assume that citizens have an attachment to their region or country of origin (Mansoorian and Myers, 1997; Wellisch, 1994). Accordingly, migration entails costs, both psychic and financial, associated with leaving their preferred place of residence. ${ }^{8}$ I assume the cost of migration $v$ varies across individuals, according to the probability distribution function $\phi(v)$, with associated cumulative distribution function $\Phi(v)$ (Mansoorian and Myers, 1997; Wellisch, 1994). Citizens migrate only when the difference in per-capita climate damages between country 2 and country 1 is large enough 
to offset the opportunity cost of migrating, which implies a cutoff value: ${ }^{9}$

$$
\hat{v}=(\beta-1) d(Z) \text {. }
$$

The implication is that the population residing in country 1 , combining both original inhabitants and migrants, is

$$
\alpha=\alpha_{0}+\int^{\hat{v}} \phi(v) d v
$$

As the carbon stock changes, damages change, and so the change in population resulting from in-migration is:

$$
\begin{aligned}
\dot{\alpha} & =\phi(\hat{v})(\beta-1) d^{\prime}(Z) \dot{Z} \\
& =\phi(\hat{v})(\beta-1) d^{\prime}(Z)(Q-k Z),
\end{aligned}
$$

where I made use of eq. (1) to substitute for $\dot{Z}$. As $\beta>1$ and $d^{\prime}(Z)>0$, the rate of migration into country 1 is positively related to the rate of change in the carbon stock.

The decision-maker in country 1 cares only about the well-being of its native population. This well-being depends on the utility associated with the initial population, less the damages borne by the initial population, plus any profits resulting from the production of the consumption good. Because the initial citizenry of country 1 bears some disutility from carbon-related damages, the government of country 1 has an incentive to take some action to reduce the flow of carbon emissions, which I assume they do by choosing the time path 
of production. In addition, the residents of country 1 bear crowding externalities when the population in 1 rises because of in-migration. I capture this effect through the function $E(\alpha)$, which I assume is increasing. For expositional simplicity, I assume $E=\eta \alpha$. These crowding externalities could reflect greater demand on infrastructure or social services, or

they could reflect a general preference to be in a more familiar society. ${ }^{10}$ In any event, this externality induces a disutility associated with in-migration, which likely leads to political pressure on the government in country 1 to take actions that impede in-migration. In particular, it creates a motive for the government in country 1 to take greater actions to reduce the flow of carbon emissions. ${ }^{11}$

\section{Analysis when migration is not feasible}

I now describe the general optimization problem in the absence of migration, both from the private perspective of the government in country 1 and from the combined (social) perspective. These results can be thought of as a benchmark against which the corresponding problems that arise when migration is possible.

\subsection{Privately optimal path}

In the absence of a mythical social planner, no authority has the ability to intervene and enforce cooperation; countries will act only if their efforts ultimately serve their own interest (Sigman, 2002). In this context, I assume the government of country 1 wishes to maximize the present discounted value of the net benefits accruing to its citizens, which 
equals the sum of consumer and producer surplus - or equivalently, the sum of consumer utility and firm s' profits - net of climate damages, and firm profits, net of climate damages. Accordingly, its dynamic optimization problem is to

$$
\begin{aligned}
& \max _{Q} \int_{0}^{\infty} e^{-r t}\left\{\left[u_{1}\left(Q_{1}\right)-d(Z)\right] \alpha_{0}+p(Q) Q-c(Q)\right\} \mathrm{dt} \\
& \text { subject to } \dot{Z}(t)=Q-k Z ; Z(0)=Z_{0} .
\end{aligned}
$$

The solution to this problem is based on the current-value Hamiltonian:

$$
\mathcal{H}_{p, n m}=\alpha_{0}\left[u_{1}\left(Q_{1}\right)-d(Z)\right]+p(Q) Q-c(Q)+\theta(Q-k Z),
$$

where $\theta$ is the shadow value country 1 places on the carbon stock. The optimal time path of production mazimizes the current-value Hamiltonian at each point in time:

$$
\alpha_{0} u_{1}^{\prime}\left(Q_{1}\right)\left(\partial Q_{1} / \partial Q\right)+p(Q)+p^{\prime}(Q) Q-c^{\prime}(Q)+\theta=0
$$

The optimal production rate balances the marginal impact on flow benefits to country 1 , as measured by the sum of aggregate marginal utility and marginal profits, against the imputed marginal value of an increment in the carbon stock, as measured by the shadow value. (Because the carbon stock is a bad, one expects its marginal value to be negative.) 
In addition, there is an equation of motion governing the evolution of the shadow value:

$$
\dot{\theta}=(r+k) \theta+\alpha_{0} d^{\prime}(Z)
$$

There is also a transversality condition governing the optimal path, which can be interpreted as requiring the system to converge to a long-run equilibrium, i.e., a steady state.

At steady state, the shadow value, optimal level of production and carbon stock all come to a rest. In light of eq. (7), the long-run equilibrium shadow value is the capitalized level of (negative) marginal damages from the carbon stock borne in country 1 :

$$
\hat{\theta}=-\left(\frac{\alpha_{0}}{r+k}\right) d^{\prime}(\hat{Z})
$$

where $\hat{Z}$ is the steady state value of the carbon stock.

\subsection{Socially optimal path}

Now suppose there is a global social planner whose goal is to choose the time paths of production so as to maximize the discounted flow of combined payoffs. These combined payoffs equal the sum of the two countries' utilities, plus profits, less climate damages. The 
social planner's dynamic optimization problem is to:

$$
\begin{aligned}
\max _{Q} & \int_{0}^{\infty} e^{-r t}\left\{\alpha_{0} u_{1}\left(Q_{1}\right)+\left(1-\alpha_{0}\right) u_{2}\left(Q_{2}\right)\right. \\
& \left.-\left(\alpha_{0}+\left(1-\alpha_{0}\right) \beta\right) d(Z)+p(Q) Q-c(Q)\right\} \mathrm{dt}
\end{aligned}
$$$$
\text { subject to } \dot{Z}(t)=Q-k Z ; Z(0)=Z_{0} \text {. }
$$

The solution to this problem is based on the current-value Hamiltonian:

$$
\begin{aligned}
\mathcal{H}_{s, n m}=\alpha_{0} u_{1}\left(Q_{1}\right)+\left(1-\alpha_{0}\right) u_{2}\left(Q_{2}\right) & -\left(\alpha_{0}+\left(1-\alpha_{0}\right) \beta\right) d(Z)+p(Q) Q-c(Q) \\
& +m(Q-k Z),
\end{aligned}
$$

where $m$ is the shadow value the social planner places on the carbon stock, $Q_{2}=Q-Q_{1}$, and where it is understood that $Q_{1}$ adjusts in accordance with the equi-marginal principle described above. The optimal level of production then solves

$$
\alpha_{0} u_{1}^{\prime}\left(Q_{1}\right)\left(\partial Q_{1} / \partial Q\right)+\left(1-\alpha_{0}\right) u_{2}^{\prime}\left(Q_{2}\right)\left(\partial Q_{2} / \partial Q\right)+p(Q)+p^{\prime}(Q) Q-c^{\prime}(Q)+m=0
$$

Since $\partial Q_{2} / \partial Q=1-\partial Q_{1} / \partial Q$ and $u_{1}^{\prime}\left(Q_{1}\right)=u_{2}^{\prime}\left(Q_{2}\right)$ (because of the equi-marginal principle), the optimality condition for the social planner's choice of $Q$ can be simplified to

$$
u_{1}^{\prime}\left(Q_{1}\right)\left[\alpha_{0} \partial Q_{1} / \partial Q+\left(1-\alpha_{0}\right)\left(1-\partial Q_{1} / \partial Q\right)\right]+p(Q)+p^{\prime}(Q) Q-c^{\prime}(Q)+m=0
$$


Comparing against the private optimality condition for country 1 , two differences are apparent: the social planner gives weight to the marginal benefit of consumption in country 2 , and she places a different shadow value on the carbon stock. In general, one expects the social shadow value to be larger in magnitude than the private shadow value (since adverse effects on country 2 are given weight), so there is a trade-off.

The social planner's optimal time path of production is also influenced by the equation of motion for the social shadow value of the carbon stock:

$$
\dot{m}=(r+k) m+\left(\alpha_{0}+\left(1-\alpha_{0}\right) \beta\right) d^{\prime}(Z) .
$$

Comparing against the equation of motion governing the private shadow value, it is apparent that $m$ is subject to a larger negative influence; this suggests the social shadow value is larger in magnitude than the private value, as I noted above. Also, there social planner's solution is governed by a transversality condition; as with the privately optimal path, this can be interpreted as requiring the system to converge to a steady state. Here, the steady state shadow value is the combined capitalized level of (negative) marginal damages from the carbon stock:

$$
m^{*}=-\left(\frac{\alpha_{0}+\left(1-\alpha_{0}\right) \beta}{r+k}\right) d^{\prime}\left(Z^{*}\right),
$$

where $Z^{*}$ is the steady state value of the carbon stock associated with the socially optimal production path. This shadow value is generally larger in magnitude than is the privately optimal level, and corresponds to a smaller long-run carbon stock (and production level); 
this is a manifestation of the global public bad nature of the problem: in essence, country 1 is exposing parties in country 2 to an externality associated with climate change.

\section{Analysis when migration is feasible}

Consider next the situation where migration can occur. While the potential gains associated with relocation are available to all citizens originally living in country 2, I assume migrants' net gain from moving are heterogeneously distributed. In addition, the original inhabitants in country 1 suffer a loss from increased crowding.

\subsection{Privately optimal path}

As in sub-section 3.1, the government of country 1 only cares about net benefits accruing to its native citizens; here, it also considers the costs its citizenry associates with in-migration. Accordingly, the government in country 1 solves the dynamic optimization problem:

$$
\begin{gathered}
\max _{Q} \int_{0}^{\infty} e^{-r t}\left\{\left[u_{1}\left(Q_{1}\right)-d(Z)\right] \alpha_{0}+p(Q) Q-c(Q)-\eta \alpha\right\} \mathrm{dt} \\
\text { subject to } \dot{Z}(t)=Q-k Z ; \dot{\alpha}=\phi(\hat{v})(\beta-1) d^{\prime}(Z)[Q-k Z] ; Z(0)=Z_{0}, \alpha(0)=\alpha_{0} .
\end{gathered}
$$

The solution to this problem is based on the current-value Hamiltonian:

$$
\mathcal{H}_{p, m}=\alpha_{0}\left[u_{1}\left(Q_{1}\right)-d(Z)\right]+p(Q) Q-c(Q)-\eta \alpha+\mu(Q-k Z)+\lambda \phi(\hat{v})(\beta-1) d^{\prime}(Z)[Q-k Z],
$$


where $\mu$ is the shadow value country 1 places on the carbon stock and $\lambda$ is the shadow value country 1 places on in-migration. The optimal time path of production mazimizes the current-value Hamiltonian at each point in time:

$$
\alpha_{0} u_{1}^{\prime}\left(Q_{1}\right)\left(\partial Q_{1} / \partial Q\right)+p(Q)+p^{\prime}(Q) Q-c^{\prime}(Q)+\mu+\lambda \phi(\hat{v})(\beta-1) d^{\prime}(Z)=0 .
$$

Comparing this condition against eq. (6), the decision-maker in country 1 takes the additional cost resulting from in-migration into account. Ceterus paribus, this extra cost will motivate country 1 to reduce production of the carbon-generating commodity. In addition, the solution to this problem is tied to the evolution of the shadow value of carbon:

$$
\begin{gathered}
\dot{\mu}=(r+k) \mu+\alpha_{0} d^{\prime}(Z) \\
-\lambda\left[\phi^{\prime}((\beta-1) d(Z))(\beta-1)^{2} d^{\prime}(Z)^{2}+\phi(\hat{v})(\beta-1)\left[d^{\prime \prime}(Z)[Q-k Z]-k d^{\prime}(Z)\right]\right],
\end{gathered}
$$

which differs from eq. (7) if $\lambda \neq 0$. There is also an equation of motion governing the shadow value of in-migration:

$$
\dot{\lambda}=r \lambda+\eta \text {. }
$$

Also as above, the solution is governed by transversality conditions - here, there is one for each shadow value. These conditions require either that the corresponding state variable ( $Z$ for $\mu, \alpha$ for $\lambda$ ) converge to a steady state value, or that the long-run shadow value is nil. Because of the first term in eq. (14) for in-migration, the transversality condition requires 
that $\dot{\lambda}=0$, so that either $\alpha \leq \alpha_{0}$ or $\lambda=-\eta / r$. Because the first possibility is empirically implausible, I focus on the second possibility going forward.

As climate damages mount in country 2 , some citizens migrate to country 1 , so as to reduce the damages they perceive they are exposed to. This migration generates crowding costs in country 1 , which leads the upstream decision maker to consider an extra cost; this induces a crude form of an implicit tax on production. Accordingly, the government in country 1 may be motivated to amplify their use of a pollution control instrument, so as to blunt the migratory effect. They may also be motivated to take actions that directly impede migration, e.g. border controls. To the extent that such efforts are less costly than adjusting output one expects country 1 would be less inclined to lower production, so the effect I have described would be diminished.

\subsection{Socially optimal path}

As in sub-section 3.2, the social planner cares about the discounted flow of combined payoffs. These combined payoffs equal the sum of the two countries' utilities, plus profits from production, less combined damages from the carbon stock, less the costs from in-migration; the social planner's dynamic optimization problem is now:

$$
\begin{aligned}
\max _{Q} & \int_{0}^{\infty} e^{-r t}\left\{\alpha_{0} u_{1}\left(Q_{1}\right)+\left(1-\alpha_{0}\right) u_{2}\left(Q_{2}\right)\right. \\
& -[\alpha+(1-\alpha) \beta] d(Z)+p(Q) Q-c(Q)-\eta \alpha\} \mathrm{dt} \\
& \text { subject to } \dot{Z}(t)=Q-k Z ; \dot{\alpha}=\phi(\hat{v})(\beta-1) d^{\prime}(Z)(Q-k Z) ; \alpha(0)=\alpha_{0} ; Z(0)=Z_{0} .
\end{aligned}
$$


The solution to this problem is based on the current-value Hamiltonian:

$$
\begin{aligned}
\mathcal{H}_{s, m} & =\alpha_{0} u_{1}\left(Q_{1}\right)+\left(1-\alpha_{0}\right) u_{2}\left(Q_{2}\right)-[\alpha+(1-\alpha) \beta] d(Z)+p(Q) Q-c(Q) \\
& -\eta \alpha+m_{Z}(Q-k Z)+m_{\alpha}\left(\phi(\hat{\mathrm{v}})(\beta-1) d^{\prime}(Z)(Q-k Z)\right),
\end{aligned}
$$

where $m_{Z}$ is the social shadow value of the carbon stock and $m_{\alpha}$ is the social shadow value of migration into country 1 . Noting that $\partial Q_{2} / \partial Q=1-\partial Q_{1} / \partial Q$ and $u_{1}^{\prime}\left(Q_{1}\right)=u_{2}^{\prime}\left(Q_{2}\right)$, as explained above, the socially optimal level of production in country 1 satisfies:

$$
\begin{gathered}
\alpha_{0} u_{1}^{\prime}\left(Q_{1}\right) \partial Q_{1} / \partial Q+p(Q)+p^{\prime}(Q) Q-c^{\prime}(Q)+m_{Z}+m_{\alpha} \phi(\hat{v})(\beta-1) d^{\prime}(Z)= \\
-\left(1-\alpha_{0}\right)\left(1-\partial Q_{1} / \partial Q\right) u_{1}^{\prime}\left(Q_{1}\right) .
\end{gathered}
$$

Comparing against the first-order condition for the private optimization problem in subsection 4.1, one sees three differences. These differences arise from the potential distinction between the private and social shadow values on carbon and in-migration, as well as the fact the social planner cares about impacts on citizens in country 2 , while the decisionmaker in country 1 does not. This latter difference is reflected in the term appearing on the right-hand side of eq. (16). In general, these differences imply the privately optimal plan differs from the socially optimal (first-best) plan. This result contrasts with Myers (1990), who finds that privately optimal behavior can yield a first-best outcome in the presence of migration. The key difference is that he did not include cross-boundary externalities, while such spillovers are a central feature of my model. 
In addition, the social planner's solution is influenced by the equation of motion for the social shadow value of the carbon stock:

$$
\begin{gathered}
\dot{m}_{Z}=(r+k) m_{Z}+\left(\alpha_{0}+\left(1-\alpha_{0}\right) \beta\right) d^{\prime}(Z) \\
-m_{Z}\left[\phi^{\prime}((\beta-1) d(Z))(\beta-1)^{2} d^{\prime}(Z)^{2}+\phi(\hat{v})(\beta-1)\left[d^{\prime \prime}(Z)[Q-k Z]-k d^{\prime}(Z)\right]\right],
\end{gathered}
$$

and the equation of motion governing the social shadow value of migration into country 1 :

$$
\dot{m}_{\alpha}=r m_{\alpha}+\eta+(\beta-1) d^{\prime}(Z) .
$$

The equations of motion governing the social shadow values differs from the corresponding equations of motion for the private problem because the social planner takes impacts on citizens in country 2 into account. In particular, when some of these former country 2 citizens migrate the damages they suffer are reduced; the social planner values this reduction in aggregate damages, while the private decision-maker for country 1 does not. Similarly, the evolution of the social shadow value of carbon depends on damages borne by all citizens, while the evolution of the private shadow value for the decision-maker in country 1 depends only on the original residents of country 1 . As such, the magnitude of the (negative) social value rises faster for the social planner than it does for the private decision-maker.

This problem is more complex than the three other problems analyzed above, as the solution here depends on more equations (five, as opposed to three: eqs. (1), (4), and (16)(18)). Despite this extra complexity, it is possible to draw certain comparisons, as discussed 
in subsection 5.5 below.

\section{Linear-Quadratic Example}

In the general framework described above, it is difficult to obtain further insights. Accordingly, I turn my attention to a specific example in which analytic results are more readily obtained. In this simplified variant of the model, the key ingredients are linear-quadratic functions. Linear-quadratic models are considered to be a good approximation for more general problems and are characterized by equations of motion being linear in state and control variables and objective functionals being quadratic in state and control variables.

In this variant of the model, I assume inverse demand in country $k$ is linear . To minimize notational clutter, I focus on a stark version of this example, where the slopes of demand relations are equal across the two countries $\left(b_{1}=b_{2}=b\right)$, though intercepts can differ. Quantity demanded is then $Q_{i}=\left(A_{i}-p\right) / b$ in country $i=1,2$. Aggregate utility in country $k$ is the area under inverse demand:

$$
U_{k}=\frac{b}{2} Q_{k}^{2}, \quad k=1,2
$$

At each point in time, production is divided between the two countries to equate prices; as

a result, $Q=Q_{1}+Q_{2}=A_{1}+A_{2}-2 b p$, and so $p=\frac{A_{1}+A_{2}}{2}-\frac{b}{2} Q$. Accordingly, consumption 
levels in the two countries are

$$
Q_{i}=\frac{Q}{2}+\Delta_{i}, i=1,2
$$

where $\Delta_{1}=\frac{A_{1}-A_{2}}{2 b}=-\Delta_{2}$. I also assume that supply is linear. Letting $p$ the price received by sellers (all of whom are located in country 1 ), quantity supplied is $Q=p / c$; this corresponds to assuming that marginal costs are linear, with slope $c$. I also assume the damage function is line: $d(Z)=\delta Z$, which implies a constant marginal damage $\delta$. While stark, this assumption greatly facilitates the analytic discussion below. The discount rate is $r$ for both countries. Finally, I assume migration costs for citizens in country 2 are uniformly distributed, which implies the probability density function is constant; I denote this constant by $\varphi$.

With these functional forms, it is relatively straightforward to derive the characterizations for optimal production, the associated path of carbon stocks and the shadow value of atmospheric carbon in each of the regimes. In the following subsections, I discuss these equilibrium values; derivations are relegated to the Appendix.

\subsection{Privately optimal solution - no migration}

I start by discussing the problem confronting the decision-maker in country 1 in the absence of migration. As I show in section 7.1 in the Appendix, the optimal rate of production is

$$
Q=\frac{3 A_{1}+A_{2}}{3 b+4 c}+\frac{4}{3 b+4 c} \theta,
$$


where $\theta$ is country 1's shadow value on atmospheric carbon. The shadow value follows an exponential path, which then implies that the production rate and carbon stock also follow an exponential path. The time path for the carbon stock is:

$$
Z(t)=\left(Z_{0}-\hat{Z}\right) e^{-k t}+\hat{Z},
$$

where

$$
\hat{Z}=\frac{(r+k)\left(3 A_{1}+A_{2}\right)}{k(r+k)(3 b+4 c)+4 \delta \alpha_{0}}
$$

is the long-run level of the carbon stock.

\subsection{Socially optimal solution - no migration}

Now suppose there is a global social planner, whose goal is to choose time path of production $Q$ so as to maximize the discounted flow of combined payoffs. As I show in section 7.2 of the Appendix, the optimal rate of production is

$$
Q=\frac{A_{1}+A_{2}}{b+2 c}+\left(\frac{2}{b+2 c}\right) m=0,
$$

where $m$ is shadow value of the carbon stock for the social planner's problem. Similar to the preceding subsection, the shadow value in the social planner's problem follows an exponential path, as do the production rate and the carbon stock. The time path for the 
carbon stock is

$$
Z(t)=\left(Z_{0}-Z^{*}\right) e^{-k t}+Z^{*}
$$

where

$$
Z^{*}=\frac{(r+k)\left(A_{1}+A_{2}\right)}{2 \delta\left[\alpha_{0}+\beta\left(1-\alpha_{0}\right)\right]\left(A_{1}+A_{2}\right)+k(r+k)(b+2 c)}
$$

is the long-run level of the carbon stock

\subsection{Privately optimal solution - migration}

When migration occurs, the inflow of migrants imposes costs on country 1 . The decisionmaker is now motivated to consider the effect of carbon emissions from country 1 upon damages borne by citizens in country 2. Accordingly, as I show in section 7.3 of the Appendix, the optimal level of production is now influenced by two shadow prices: one for the carbon stock, $\mu$, and one for the population in country $1, \lambda$ :

$$
Q=\frac{3 A_{1}+A_{2}}{3 b+4 c}+\left(\frac{4}{3 b+4 c}\right)(\mu+\lambda \varphi(\beta-1) \delta),
$$

where $\mu$ is the private shadow value of the carbon stock and $\lambda$ is the private shadow value of in-migration.

As per-capita marginal damages are larger in country 2 than country 1 (i.e., $(\beta-1) \delta Z>$ 0 ) and the probability density associated with opportunity costs of relocation is positive (i.e., $\varphi>0$ ), the last parenthetical term on the right-hand side of eq. 27) will generally exceed $\mu$ in magnitude. On the other hand, the marginal effect of an increase in production 
is the same as in the privately optimal program without migration. It follows that the decision maker for country 1 is inclined to select a smaller rate of production in the presence of in-migration.

As I show in section 7.3 of the Appendix, the time paths of both output and the carbon stock decline exponentially to their respective long-run equilibrium levels. The time path of the carbon stock is:

$$
Z(t)=\left(Z_{0}-\hat{Z}\right) e^{-k t}+\hat{Z}
$$

where

$$
\hat{Z}=\frac{(r+k)\left(3 A_{1}+A_{2}\right)}{k(r+k)(3 b+4 c)+4 \delta \alpha_{0}-4 \delta \lambda \varphi(\beta-1)}
$$

is the long-run level of the carbon stock.

Because $\lambda<0$, the denominator in this expression is larger than the denominator in eq. (23). Since the numerators in the two expressions are identical, it follows that the privately optimal steady state carbon stock is smaller in the presence of migration: $\tilde{Z}<\hat{Z}$.

\subsection{Socially optimal solution - migration}

Finally, consider the problem facing a global social planner, whose goal is to choose time path of production $Q$ so as to maximize the discounted flow of combined payoffs. As I show in section 7.4 in the Appendix, the optimal rate of production is

$$
Q=\frac{A_{1}+A_{2}}{b+2 c}+\left(\frac{2}{b+2 c}\right)\left[m_{Z}+\delta \varphi(\beta-1) m_{\alpha}\right]
$$


where $m_{Z}$ is the shadow value of the carbon stock, and $m_{\alpha}$ is the shadow value of inmigration, for the social planner's problem.

In contrast to the preceding subsections, it is difficult to solve for the explicit time path of production here. As I noted above, the solution here depends on a more complex system of equations. Despite this extra complexity, one can solve for the long-run level of the carbon stock:

$$
Z^{* *}=\frac{3\left(A_{1}+A_{2}\right)}{k(5 b+4 c)}-\left(\frac{4 \delta}{k(r+k)(5 b+4 c)}\right)[\alpha+\beta(1-\alpha)+\varphi(\beta-1)(\eta-\delta \varphi(\beta-1))] .
$$

\subsection{Comparison}

The central question in this paper is: to what extent does migration create incentives for the upstream country to lower its carbon emissions? That question has two dimensions, longand short-run. The long-run comparison is based on steady state carbon stocks with and without migration, while the short-run analysis requires a comparison of emission paths.

\subsubsection{Comparison of private optima}

The long-run implications of migration can be assessed by comparing the steady state carbon stock in the presence of migration against the steady state carbon stock in the absence of migration. For the private optimization problem, this turns on a comparison of $\hat{Z}$ and $\hat{Z}$. 
Eq. (51) in the Appendix shows that

$$
\hat{Z}=\hat{Z}-\frac{4 \eta \delta \varphi(\beta-1)}{k(r+k)(3 b+4 c)}<\hat{Z} .
$$

Thus, migration lowers the long-run carbon stock. In light of eq. (??), it then follows that the long-run production rate is also lower under migration. Since both output rates and carbon stocks decline at the rate $k$ with and without migration, it also follows that the time paths for both $Q$ and $Z$ in the presence of migration lie below the corresponding time paths in the absence of migration.

\subsubsection{Comparison of social optima}

Discerning the impact of migration upon long-run carbon stocks with and without migration turns on a comparison of $Z^{*}$ and $Z^{* *}$. As eq. (57) in the Appendix shows,

$$
Z^{* *}=Z^{*}-\frac{2 \varphi \delta(\beta-1)[\delta(\beta-1)-\eta]}{(b+2 c)} .
$$

Thus, the potential for migration will commonly reduce the long run carbon stock. Comparing time paths with and without migration is more difficult. But as the two paths start from the same initial condition, $Z_{0}$, the carbon stock path with migration must lie below the path without migration after some point in time. 


\section{Concluding Remarks}

Climate change has been called the most difficult externality problem ever confronted by humankind. This characterization is underscored by the likely human costs associated with efforts to adapt to climate damages, via migration. My goal in this paper has been to evaluate what I believe to be an under-appreciated offsetting effect from migration: that pressures upon countries that experience in-migration might encourage such countries to reduce their greenhouse-gas emissions, thereby offering benefits on a global scale. Such pressures induce a sort of pseudo carbon tax, which motivates lower emissions. I show that the long run carbon stock, and the entire time path of production, is smaller in the presence of migration, offering an offset to the costs incurred as a result of climate change.

One way to think of this problem is as a tension between two competing effects. Actions taken by country 1 generate costs borne by country 2 , through the transboundary externality associated with the carbon stock. At the same time, actions taken by citizens in country 2 impose costs on country 1 , through the costs citizens in country 1 perceive arising from in-migration. In my model, as climate damages rise, there is greater pressure on the destination country to curtail its emissions. But if country 1 thinks that some in-migration is beneficial, say because the migrants had particular skills or human capital that was deemed attractive by firms in country 1 , then one could imagine migration leading to increased, as opposed to decreased, emissions. In addition, it is conceivable that the government of country 1 could explore a variation of cooperation, wherein they commit to reduce emissions if the government of country 2 commits to stem the flow of migration. 
Such a regime has the flavor of linked policies, in the manner of Limão (2005).

In my model, the government of country 1 undertakes actions unilaterally, by reducing its output levels - and thereby partially mitigating the flow of emissions. Country 1 does not utilize other instruments, such as border controls or limits on migrants. One could imagine extending the model to allow for this alternative policy, along the lines of Ethier (1986). In such an extension, the government of country 1 could inhibit migration by expending resources; in this way, the costs associated with migration would be increased, lowering the rate of in-migration. If the cost function describing the level of expenditure required to mitigate a given level of in-migration as convex in the degree of "migration abatement", as seems plausible, then there will be an interior level of expenditures that balances the marginal cost of migration abatement against the cost of marginal cost of migration, as measured by the parameter $\eta$ in my model. In this way, the incentive to reduce emissions is partially offset. In particular, the migration control efforts would seem to lower the magnitude of the negative shadow value of in-migration. At the same time, it is unclear that such efforts are socially desirable: while the reduction of costs associated with inmigration is a tangible social benefit, this gain comes at the cost of larger emissions, and accordingly larger carbon stocks. It seems unlikely that the damages associated with this adjusted time path of carbon stocks would exactly match the net costs of limiting migration (enforcement costs less benefits from reduced in-migration), and so the inclusion of this policy lever seems likely to influence the comparison of private and social optima. It is also possible that migration policies will have other effects, not modeled in my model. 
For example, targeted immigration policies can influence the pattern of welfare payments (Storesletten, 2000).

Working against the potential global gains that emerge in this scenario are the opportunity costs born by migrants. While the monetary magnitude of these dislocation costs might not be particularly large, the non-pecuniary impact could be substantial. Accordingly, I do not argue that the net upon global net benefits associated with migration is positive. Rather, I want to point out that migration can serve a purpose, that it can induce emissions reductions that would otherwise not be forthcoming. Whether such indirect benefits are large in comparison to the opportunity costs related to migration is of course an empirical question. Perhaps in raising this possibility, this paper will encourage investigations of this empirical question. 


\section{Appendix}

In this Appendix, I present the analytics underlying the discussion in section 5 . These analytics are presented in parallel fashion to the main text: first, I work through the problem when migration is not possible, taking the private and social optimization problems in turn. Then I through the problem when migration is possible, again taking the private and social optimization problems in turns.

\subsection{Privately optimal solution, no migration}

The current-value Hamiltonian governing country 1's optimization problem in the absence of migration is:

$$
\mathcal{H}_{n m}=\frac{b}{2} Q_{1}^{2}+\left(\frac{A_{1}+A_{2}}{2}\right) Q-\left(\frac{b+c}{2}\right) Q^{2}-\alpha_{0} \delta Z+\theta(Q-k Z)
$$

where $\theta$ is the shadow value country 1 places on the atmospheric carbon stock. The necessary condition for the solution to this dynamic optimization problem is that the time path of production maximizes the current-value Hamiltonian at each point in time:

$$
b Q_{1} \frac{\partial Q_{1}}{\partial Q}+\frac{A_{1}+A_{2}}{2}-(b+c) Q+\theta=0
$$

Taking note of eq. (20), this condition implies:

$$
\frac{A_{1}-A_{2}}{4}+\frac{b}{4} Q+\frac{A_{1}+A_{2}}{2}-(b+c) Q+\theta=0
$$


rearranging yields

$$
Q=T_{0}+T_{1} \theta
$$

where $T_{0}=\frac{3 A_{1}+A_{2}}{3 b+4 c}, T_{1}=\frac{4}{3 b+4 c}$; this corresponds to eq. (21) in the text.

The solution is also governed by equations of motion for the shadow value $\theta$

$$
\dot{\theta}=(r+k) \theta+\alpha_{0} \delta
$$

as well as eq. (1). The solution is also influenced by a transversality condition, which requires convergence to a steady state.

To proceed, I time-differentiate eq. (33) and then use eqs. (1), (??) and (34) to simplify. This process yields a system of line first-order differential equations:

$$
\left(\begin{array}{c}
\dot{Q} \\
\dot{Z}
\end{array}\right)=\Lambda\left(\begin{array}{l}
Q \\
Z
\end{array}\right)+\left(\begin{array}{c}
T_{1} \alpha_{0} \delta-T_{0}(r+k) \\
0
\end{array}\right)
$$

where

$$
\Lambda=\left(\begin{array}{cc}
r+k & 0 \\
1 & -k
\end{array}\right)
$$

The solution to this differential equation is a mix of exponentials and the long-run (steady state) value. The coefficients in the exponential components are determined by the solution to the characteristic equation, $\operatorname{det}\left(\rho I_{2}+\Lambda\right)=0$, where $I_{2}$ is $2 \times 2$ identity matrix; this 
equation is:

$$
(\rho-(r+k))(\rho+k)
$$

The roots are thus $-k$ and $r+k$. Because the contribution from the second part will increase (decrease) without bound, it follows from the transversality condition that the coefficient multiplying the associated exponential term must be zero. Accordingly, both $Q$ and $Z$ decay at the rate $k$. The steady state values are found by setting $\dot{Q}=\dot{Z}$ in eq. (35):

$$
\begin{aligned}
& \hat{Q}=\frac{3 A_{1}+A_{2}}{3 b+4 c}-\frac{4 \delta \alpha_{0}}{(r+k)(3 b+4 c)}, \\
& \hat{Z}=\frac{3 A_{1}+A_{2}}{k(3 b+4 c)}-\frac{4 \delta \alpha_{0}}{k(r+k)(3 b+4 c)} .
\end{aligned}
$$

\subsection{Socially optimal solution, no migration}

The current-value Hamiltonian associated with the optimization problem confronting a social planner is

$$
\mathcal{H}_{s, n}=\frac{b}{2} Q_{1}^{2}+\frac{b}{2} Q_{2}^{2}+\left(\frac{A_{1}+A_{2}}{2}\right) Q-\left(\frac{b+c}{2}\right) Q^{2}-\left[\alpha_{0}+\beta\left(1-\alpha_{0}\right)\right] \delta Z+m(Q-k Z)
$$

where $m$ is the (cooperative) shadow value of the carbon stock. As pollution is a bad, one presumes that $m$ is negative. The necessary condition for the solution to this dynamic optimization problem requires production to maximize the current-value Hamiltonian at 
each point in time:

$$
b Q_{1} \frac{\partial Q_{1}}{\partial Q}+b Q_{2} \frac{\partial Q_{2}}{\partial Q}+\frac{A_{1}+A_{2}}{2}-(b+c) Q+m=0
$$

Taking note of eq. (20), this condition implies:

$$
\frac{b}{2} Q+A_{1}+A_{2}-(b+c) Q+m=0
$$

rearranging yields

$$
Q=T_{3}+T_{4} m
$$

where $T_{3}=\frac{A_{1}+A_{2}}{b+2 c}$ and $T_{4}=\frac{2}{b+2 c}$; this corresponds to eq. (24) in the text.

The solution also requires the evolution of the shadow value satisfy

$$
\dot{m}=(r+k) m+\left[\alpha_{0}+\beta\left(1-\alpha_{0}\right)\right] \delta,
$$

as well as eq. (1).

As with the analysis of the privately optimal problem, I proceed by time-differentiating eq. (40) and then use eqs. (1), (40) and (41) to simplify. This yields the system of differential equations:

$$
\left(\begin{array}{c}
\dot{Q} \\
\dot{Z}
\end{array}\right)=\Lambda\left(\begin{array}{c}
Q \\
Z
\end{array}\right)+\left(\begin{array}{c}
\delta\left[\alpha_{0}+\beta\left(1-\alpha_{0}\right)\right] T_{4}-(r+k) T_{3} \\
0
\end{array}\right)
$$


As above, the solutions to this system of differential equation are a combination of an exponential term that declines at rate $k$ and the long-run (steady state) values. The steady state values are found by setting $\dot{Q}=\dot{Z}$ in eq. (42):

$$
\begin{aligned}
Q^{*} & =\frac{A_{1}+A_{2}}{b+2 c}-\frac{2 \delta\left[\alpha_{0}+\beta\left(1-\alpha_{0}\right)\right]}{(r+k)(b+2 c)}, \\
Z^{*} & =\frac{A_{1}+A_{2}}{k(b+2 c)}-\frac{2 \delta\left[\alpha_{0}+\beta\left(1-\alpha_{0}\right)\right]}{k(r+k)(b+2 c)} .
\end{aligned}
$$

\subsection{Privately optimal solution with migration}

The current-value Hamiltonian governing country 1's optimization problem in the presence of migration is:

$$
\mathcal{H}_{p, m}=\frac{b}{2} Q_{1}^{2}+\left(\frac{A_{1}+A_{2}}{2}\right) Q-\left(\frac{b+c}{2}\right) Q^{2}-\eta \alpha-\alpha_{0} \delta Z+(\mu+\lambda \varphi(\beta-1) \delta)(Q-k Z)
$$

where $\mu$ is the private shadow value for the carbon stock, and $\lambda$ is the private shadow value for for in-migration. The privately optimal time path of production maximizes the currentvalue Hamiltonian at each point in time:

$$
b Q_{1} \frac{\partial Q_{1}}{\partial Q}+\frac{A_{1}+A_{2}}{2}-(b+c) Q+\mu+\lambda \delta \varphi(\beta-1)=0,
$$

which implies

$$
Q=T_{0}+T_{1} T_{2}+T_{1} \mu,
$$


where $T_{2}=\lambda \delta \varphi(\beta-1)$. The solution is also governed by equations of motion for the shadow values:

$$
\begin{aligned}
& \dot{\mu}=(r+k) \mu+\alpha_{0} \delta+k \lambda \delta \varphi(\beta-1), \\
& \dot{\lambda}=r \lambda+\eta,
\end{aligned}
$$

and eq. (1). In addition, the solution is also influenced by transversality conditions on $Z$ and $\alpha$, which require convergence to a steady state; as above, this forces $\dot{\lambda}=0$, so that $\lambda=-\eta / r$. Accordingly, $T_{2}=-\eta \delta \varphi(\beta-1) / r$, which is negative.

To proceed, I time-differentiate eq (46) and use eq. 47) to replace $\dot{\mu}$, and then combine with eq. (1) to obtain the system of differential equations:

$$
\left(\begin{array}{c}
\dot{Q} \\
\dot{Z}
\end{array}\right)=\Lambda\left(\begin{array}{c}
Q \\
Z
\end{array}\right)=\left(\begin{array}{c}
T_{1} \alpha_{0} \delta-T_{0}(r+k)+r T_{1} T_{2} \\
0
\end{array}\right)
$$

Once again, the solutions to this system of differential equation are a combination of an exponential term that declines at rate $k$ and the long-run (steady state) values. The steady state values $\hat{\hat{Q}}$ and $\hat{Z}$ can be found by setting $\dot{Q}=\dot{Z}=0$ in eq. (49); solving the resultant linear equation gives

$$
\begin{aligned}
\hat{\hat{Q}} & =\frac{3 A_{1}+A_{2}}{3 b+4 c}-\frac{4 \delta \alpha_{0}}{(r+k)(3 b+4 c)}-\frac{4 \eta \delta \varphi(\beta-1)}{(r+k)(3 b+4 c)} \\
& =\hat{Q}-\frac{4 \eta \delta \varphi(\beta-1)}{(r+k)(3 b+4 c)}
\end{aligned}
$$




$$
\begin{aligned}
\hat{Z} & =\frac{3 A_{1}+A_{2}}{k(3 b+4 c)}-\frac{4 \delta \alpha_{0}}{k(r+k)(3 b+4 c)}-\frac{4 \eta \delta \varphi(\beta-1)}{k(r+k)(3 b+4 c)} \\
& =\hat{Z}-\frac{4 \eta \delta \varphi(\beta-1)}{k(r+k)(3 b+4 c)} .
\end{aligned}
$$

\subsection{Socially optimal solution with migration}

The current-value Hamiltonian governing country 1's optimization problem in the presence of migration is:

$$
\begin{aligned}
\mathcal{H}_{s, m}=\frac{b}{2} Q_{1}^{2}+\frac{b}{2} Q_{2}^{2}+ & +\left(\frac{A_{1}+A_{2}}{2}\right) Q-\left(\frac{b+c}{2}\right) Q^{2}-\eta \alpha-[\alpha+\beta(1-\alpha)] \delta Z \\
& +\left[m_{Z}+m_{\alpha}(\varphi(\beta-1) \delta)\right](Q-k Z) .
\end{aligned}
$$

where $m_{Z}$ is the social shadow price for the carbon stock, and $m_{\alpha}$ is the social shadow price for for the population in country 1 . The necessary condition for the solution to this dynamic optimization problem is that the time path of production maximizes the currentvalue Hamiltonian at each point in time. Noting that $\frac{\partial Q_{1}}{\partial Q}=\frac{1}{2}$, one may derive:

$$
\frac{b}{2} Q+A_{1}+A_{2}-(b+c) Q+m_{Z}+m_{\alpha} \varphi(\beta-1) \delta=0 .
$$

Rearranging then yields

$$
Q=T_{3}+T_{4}\left[m_{Z}+m_{\alpha} \varphi(\beta-1) \delta\right] .
$$


The solution is also governed by equations of motion for the shadow values:

$$
\begin{aligned}
& \dot{m}_{Z}=(r+k) m_{Z}+\delta\left[\alpha+\beta(1-\alpha)+k \varphi(\beta-1) m_{\alpha}\right], \\
& \dot{m}_{\alpha}=r m_{\alpha}+\eta-\delta \varphi(\beta-1),
\end{aligned}
$$

as well as eqs. (1) and (4). The solution is also influenced by transversality conditions on $Z$ and $\alpha$, which require convergence to a steady state; as above, this forces $\dot{m}_{Z}=\dot{m}_{\alpha}=0$;.

One could proceed by time-differentiating eq. (53), and then use eq. (54) to substitute for $\dot{m}_{Z}$ and eq. (53) to substitute for $\dot{m}_{Z}$. Such an approach yields:

$$
\left.\dot{Q}=(r+k) Q-(r+k) T_{3}+T_{4} \delta[\alpha+\beta(1-\alpha)]-r T_{5}\right),
$$

where $T_{5}=T_{4} \delta \varphi(\beta-1)\left(\frac{\delta(\beta-1)-\eta}{r}\right)$. Such an approach would facilitate synthesizing the original system of five equations into a system of four equations. While this is a system of linear first-order differential equations, solving the system is a daunting task.

An alternative approach is to use the information from the system to identify the steady state. From eq. (56), one has

$$
\begin{aligned}
Q^{* *} & =T_{3}-\delta\left(\frac{T_{4}}{r+k}\right)(\alpha+\beta(1-\alpha))-\frac{r T_{5}}{r+k} \\
& =Q^{*}-\frac{r T_{5}}{r+k},
\end{aligned}
$$

which is less than $Q^{*}$. In addition, the equation governing $\dot{m}_{Z}$ indicates that the steady state 
value $m_{Z}^{* *}$ is linked to the steady state value $m_{\alpha}^{* *}$. In turn, the equation governing $\dot{m}_{\alpha}$ ties $m_{\alpha}^{* *}$ to the steady state value $\alpha^{* *}$; this level is determined by the steady state migration cost

$$
v^{* *}=(\beta-1) \delta Z^{* *}
$$

Accordingly, all three steady state values $m_{Z}^{* *}, m_{\alpha}^{* *}$ and $\alpha^{* *}$ are linked to the steady state carbon stock $Z^{* *}$. Also, from eq. (1), the steady state production rate is proportional to $Z^{* *}$. Combining all these facts, tedious algebra leads to

$$
Z^{* *}=\frac{(r+k)\left(A_{1}+A_{2}\right)-2 \delta\left(\beta+(\beta-1)\left(\varphi \eta-\alpha_{0}\right)\right)}{k(r+k)(b+2 c)-4 \varphi \delta^{2}(\beta-1)^{2}}
$$

\subsection{Comparative dynamics}

The difference between steady state carbon stocks without and with migration is:

$$
\Gamma_{1} \equiv \hat{Z}-\tilde{Z}=\frac{\left(3 A_{1}+A_{2}\right) Y}{r(r+k) X^{2}+X Y}
$$

where

$$
\begin{aligned}
& X=k(3 b+4 c)+4 \delta \alpha_{0} /(r+k), \\
& Y=4 \delta \eta \varphi(\beta-1) .
\end{aligned}
$$


A decrease in $X$, or an increase in $Y, A_{1}$ or $A_{2}$, will increase $\Gamma_{1}$. Thus, a decrease in the initial population in country $1\left(\alpha_{0}\right)$, the slope of demand $(b)$ or marginal cost $(c)$, an increase in the relative damages born in country $2(\beta)$ or a tightening of the distribution of migration costs for citizens of country 2 (which translates into an increase in $\varphi$ ) will increase the wedge between $\hat{Z}$ and $\tilde{Z}$. The effect of a change in $r, k$ or $\delta$ is ambiguous.

The difference between the terms in the radical component in the exponential parameters $\rho_{3}$ and $\rho_{1}$ is: 


$$
\Gamma_{2} \equiv \hat{Z}-\tilde{Z}=-\frac{16 k \delta \varphi(\beta-1) \eta}{r(3 b+4 c)}
$$

An increase in $k, \delta, \varphi, \beta$ or $\eta$, or a decrease in $b, c$ or $r$ will increase the magnitude of $\Gamma_{2}$, and hence reduce $\rho_{3}$. Such a change would translate into an increase in the difference between the shadow value of carbon in the presence of migration, as compared to the absence of migration.

\section{References}

Auffhammer, M. and Vincent, J. R. (2012). Unobserved time effects confound the identification of climate change impacts, Proceedings of the National Academy of Science 109: 11973-11974.

Barrios Puente, G., Perez, F. and Gitter, R. J. (2015). The effect of rainfall on migration from Mexico to the U.S., International Migration Review pp. 1-20.

Bayramoglu, B. (2006). Transboundary pollution in the black sea: Comparison of institutional arrangements, Environmental and Resource Economics 35: 289-325.

Beine, M., Docquier, F. and Ōzden, Ç. (2011). Diasporas, Journal of Development Economics 95: 30-41.

Beine, M. and Parsons, C. (2015). Climatic factors as determinants of international migration, Scandinavian Journal of Economics 117: 723-767. 
Benhabib, J. (1996). On the political economy of immigration, European Economic Review 40: $1737-1743$.

Bertoli, S. and Moraga, J. F.-H. (2013). Multilateral resistance to migration, Journal of Development Economics 102: 79-100.

Black, R., Bennett, S. R. G., Thomas, S. M. and Beddington, J. R. (2011). Climate change: Migration as adaptation, Nature 478: 447-449.

Bohra-Mishraa, P., Oppenheimer, M. and Hsiang, S. (2014). Nonlinear permanent migration response to climatic variations but minimal response to disasters, Proceedings of the National Academy of Science 111: 9780-9785.

Borjas, G. J. (2003). The labor demand curve is downward sloping: Reexamining the impact of immigration on the labor market, The Quarterly Journal of Economics 118: $1335-1374$.

Cattaneo, C. and Peri, G. (2016). The migration response to increasing temperatures, Journal of Development Economics 122: 127-146.

Chopra, K. and Gulati, S. (2001). Migration, Common Property Resources and Environmental Degradation, Sage, London.

Coniglio, N. D. and Pesce, G. (2015). Climate variability and international migration: An empirical analysis, Environment and Development Economics 20: 434-468. 
Desmet, K. and Rossi-Hansberg, E. (2015). On the spatial economic impact of global warming, Journal of Urban Economics 88: 16-37.

Dockner, E. and van Long, N. (1993). International pollution control: Cooperative versus non-cooperative strategies, Journal of Environmental Economics and Management 25: 13-29.

Drabo, A. and Mbaye, L. (2015). Natural disasters, migration and education: An empirical analysis in developing countries, Environment and Development Economics 20: 767796.

Ethier, W. J. (1986). Illegal immigration: The host?country problem, American Economic Review 76: 56-71.

Facchini, G. and Willmann, G. (2005). The political economy of international factor mobility, Journal of International Economics 67: 201-219.

Gray, C. L. and Mueller, V. (2012). Natural disasters and population mobility in Bangladesh, Proceedings of the National Academy of Science 109: 6000-6005.

Hallegatte, S., Bangalore, M., Bonzanigo, L., Fay, M., Kane, T., Narloch, U., Rozenberg, J., Treguer, D. and Vogt-Schilb, A. (2016). Shock Waves: Managing the Impacts of Climate Change on Poverty, World Bank, Washington, DC. Climate Change and Development Series.

IPCC (2014). Climate Change 2014: Synthesis Report. Contribution of Working Groups 
I, II and III to the Fifth Assessment Report of the Intergovernmental Panel on Climate Change, IPCC, Geneva, Switzerland. Pachauri, R. K. and Meyer, L. A., eds.

Lilleør, H. B. and Van den Broeck, K. (2011). Economic drivers of migration and climate change in LDCs, Global Environmental Change 21: S70-S81.

Limão, N. (2005). Trade policy, cross?border externalities and lobbies: Do linked agreements enforce more cooperative outcomes?, Journal of International Economics 67: 175-199.

List, J. and Mason, C. F. (2001). Optimal institutional arrangements transboundary pollutants in a second-best world: Evidence from a differential game with asymmetric players, Journal of Environmental Economics and Management 42: 277-296.

Maler, K. and de Zeeuw, A. (1998). The acid rain differential game, Environmental and Resource Economics 12: 167-184.

Mansoorian, A. and Myers, G. M. (1997). On the consequences of government objectives for economies with mobile populations, Journal of Public Economics 63: 265-281.

McLeman, R. and Smit, B. (2006). Migration as an adaptation to climate change, Climatic Change 76: 31-53.

Mendelsohn, R. (2012). The economics of adaptation to climate change in developing countries, Climate Change Economics 3: 1250006-1 - 1250006-21. 
Millock, K. (2015). Migration and environment, Annual Review of Resource Economics 7: $35-60$.

Moraga, J. F.-H. (2013). Understanding different migrant selection patterns in rural and urban Mexico, Journal of Development Economics 103: 182-201.

Mueller, V., Gray, C. L. and Kosec, K. (2014). Heat stress increases long-term human migration in rural Pakistan, Nature Climate Change 4: 182-185.

Munshi, K. (2003). Networks in the modern economy: Mexican migrants in the U. S. labor market, The Quarterly Journal of Economics 118: 549-599.

Myers, G. M. (1990). Optimality, free mobility, and the regional authority in a federation, Journal of Public Economics 43: 107-121.

Ottaviano, G. I. P. and Peri, G. (2012). Rethinking the effect of immigration on wages, Journal of the European Economic Association 10: 152-197.

Piguet, E., Pécoud, A. and de Guchteneire, P. (2011). Migration and climate change: An overview, Refugee Survey Quarterly 30: 1-23.

Schlenker, W. and Roberts, M. J. R. (2009). Nonlinear temperature effects indicate severe damages to US crop yields under climate change, Proceedings of the National Academy of Science 106: 15594-15598.

Sigman, H. (2002). International spillovers and water quality in rivers: Do countries free ride?, American Economic Review 92: 1152-1159. 
Storesletten, K. (2000). Sustaining fiscal policy through immigration, Journal of Political Economy 108: 300-323.

Wellisch, D. (1994). Interregional spillovers in the presence of perfect and imperfect household mobility, Journal of Public Economics 55: 167-184.

\section{Notes}

1 The report goes on to say "[m]igration can be an important way of adapting to extreme weather events and climate change impacts, and thus of reducing impacts that lower welfare," particularly in coastal areas where adaptation is difficult or extremely costly Hallegatte et al. (2016, p. 160). Empirical evidence of such pressures has been inconsistent. Bohra-Mishraa et al. (2014) argue that climate change can lead to permanent migration, while disasters exert little migratory pressure. Beine and Parsons (2015) corroborates the latter finding, but find no evidence that climate change has directly lead to increased migration; they do find indirect pressures can arise by the adverse effect of climate change upon earnings in the country from which individuals migrate, in a similarly structured study, with a more granular definition of time periods (which allows a more precise measurement of temperature- and precipitation anomalies), Coniglio and Pesce(2015) find evidence that persistent changes in precipitation patterns, as measured by the intra-annual variability, significantly increase out-migration. The conflicting evidence from these studies points to 
a subtle empirical concern, namely that it may be difficult to distinguish between various causal effects (Auffhammer and Vincent, 2012; Lilleør and Van den Broeck, 2011; Piguet et al., 2011). There is also some debate as to the efficacy of migration from poor countries. Drabo and Mbaye (2015) argues that natural disasters lead to migration from less developed countries, particularly by individuals with higher skill or human capital levels, while Cattaneo and Peri (2016) argues that adverse impacts from climate change upon agriculture are likely to lower migration rates from very poor countries (though they argue that such effects increase migration from middle-income countries, e.g. Mexico).

2 A notable exception is Desmet and Rossi-Hansberg (2015), which provides a numerical investigation of the potential for trade restriction, energy taxes or green subsidies to mitigate greenhouse gas emissions when geographically heterogeneous climate damages can motivate migration.

3 List and Mason (2001) adopt a similar simplification, where emissions come from one country only; they explore the potential for differing national policies to produce preferable outcomes to a common pollution control measure. The assumption that the good is exported from country 1 to country 2 is made for analytic convenience alone: it allows me to abstract from differences in utility between the two countries that arise from consumption of the good - as a result, migration is only motivated by climate damages. For an alternative modeling approach that focuses on decentralized decision-makers, and where spatially distributed climate-related damages can motivate migration, see Desmet and Rossi-Hansberg (2015). 
4 There is a literature that analyzes the potential for migration to alleviate externalities in a static setting (Mansoorian and Myers, 1997; Wellisch, 1994); my paper extends this analysis to a dynamic setting. My paper also extends the dynamic transboundary pollution literature. As a general rule, papers in that literature compare the cooperative scenario and non-cooperative scenario, in which each country's environmental policy is selected to promote its own interest, given the other country's emission standards (Bayramoglu, 2006, Dockner and van Long, 1993; List and Mason, 2001; Maler and de Zeeuw, 1998). This literature typically neglects the potential for migration to vitiate transboundary externalities.

5 This pressure could manifest in terms of substantial increases in precipitation patterns, which might adversely impact agricultural opportunities, or increased temperatures, which could yield sufficient stress as to induce migration. Gray and Mueller (2012) offer evidence that climate change has contributed to migratory pressures in Bangladesh. Mueller et al. (2014) argue that heat stress has lead to permanent migration from Pakistan.

6 Such a policy response was recently suggested by German Chancellor Merkel on the $30^{t h}$ anniversary of the ministry of the environment (see https: / / www . bundesregierung. de/Content/EN/Artikel/2016/06_en/2016-06-03-bmub-30-jahre_en.html); this sentiment was echoed by the minister for the environment (see http://www.bmub.bund.de/ presse/reden/detailansicht/artikel/rede-von-dr-barbara-hendricksanlaesslich-des-30-jaehrigen-jubilaeums-des-bmub/\#). These sentiments are manifested in recent funding increases allocated to the German ministry for economic cooperation and development, which were linked to migration and climate change (see https:// 
WwW.bmz.de/en/press/aktuelleMeldungen/2015/juli/20150701_pm_052_Large-

increase-in-BMZ-budget-more-funding-for-countries-affected-by-

displacement-and-crisis/index.html).

7 To reduce notational clutter, I generally suppress the time argument $t$ in the pursuant discussion.

8 Migration costs can depend on a number of factors, including physical distance that must be traversed, social, cultural and linguistic characteristics of the original and destination country, skill and human capital endowments of the migrant, and the size of the expatriate community in the destination country (Beine et al., 2011); these costs may also depend on whether the individual migrates from an urban or rural environment (Moraga, 2013). Migration between two countries is also likely to be influenced by alternative possible destinations (Bertoli and Moraga, 2013). I abstract from the possibility of multiple destinations so as to sharpen the focus of my analysis.

9 In Mansoorian and Myers (1997) and Wellisch (1994), agents relocate when the change in net utility, reflecting per-capita utility from consumption as well as any externalitybased damages, is sufficient to cover the opportunity cost or moving. I am implicitly assuming agents' utility is determined by their place of origin, i.e., an agent's tastes do not change just because they move from country 2 to country 1 . As the price of the consumption good is the same in both countries, it follows that agents do not incur a change in utility hen they move; the only impact on their net payoffs comes from the exposure to climate-based 
damages, which is lower in country 1 than country 2. My focus on climate-based motives for migration is consistent with "push" motives, which are broadly related to environmental considerations (Chopra and Gulati, 2001). As Mendelsohn (2012) points out, relocation is a discrete adaptation to an inter-temporal optimization problem, i.e., agents migrate when they perceive that so doing will increaser the present discounted flow of payoffs sufficiently as to offset any adjustment costs.

10 It is also conceivable that in-migration will adversely impact wages paid to the native population, a point which is somewhat controversial in the extant literature. For example, Borjas (2003) finds a small negative impact of migration upon wages, largely clustered in low-skill markets (however, his Figure II suggests that impacts on wage growth associated with relatively slow rates of in-migration are unlikely to be statistically important). By contrast, Ottaviano and Peri (2012) finds that migration induces a slight positive impact on wages. It may be the case that early immigrants have higher skill levels (Beine et al., 2011), so that they produce benefits to the destination country; one expects these benefits to diminish as the stock of immigrants rises, so that any adverse pecuniary impacts borne by individuals in country 1 are likely to increase as $\alpha$ rises. My analysis implicitly includes any impact on wages in the crowding function.

11 Facchini and Willmann 2005) report a number of examples of such lobbying pressure, which they use as motivation for a political economy model of factor protection. Such protection could be manifested in terms of an immigration policy, as in Benhabib (1996), or in some form of border controls. This sort of policy could be interpreted as the expenditure 
of resources by the government of country 1 to induce an increase in migration costs from country 2, as in Ethier (1986). 